\title{
Electrochemical Synthesis of Alkyl Nitroaromatic Compounds
}

Iluminada Gallardo*, Gonzalo Guirado, Jordi Marquet

Departament de Química, Universitat Autònoma de Barcelona E-08193 Bellaterra, Barcelona (Spain)

Fax: (+34) 93-581-2920

e-mail: lluminada.Gallardo@uab.es

\section{Supporting Information}

Contents: Cyclic Voltammetry Experiments

\section{Cyclic Voltammetry Experiments}

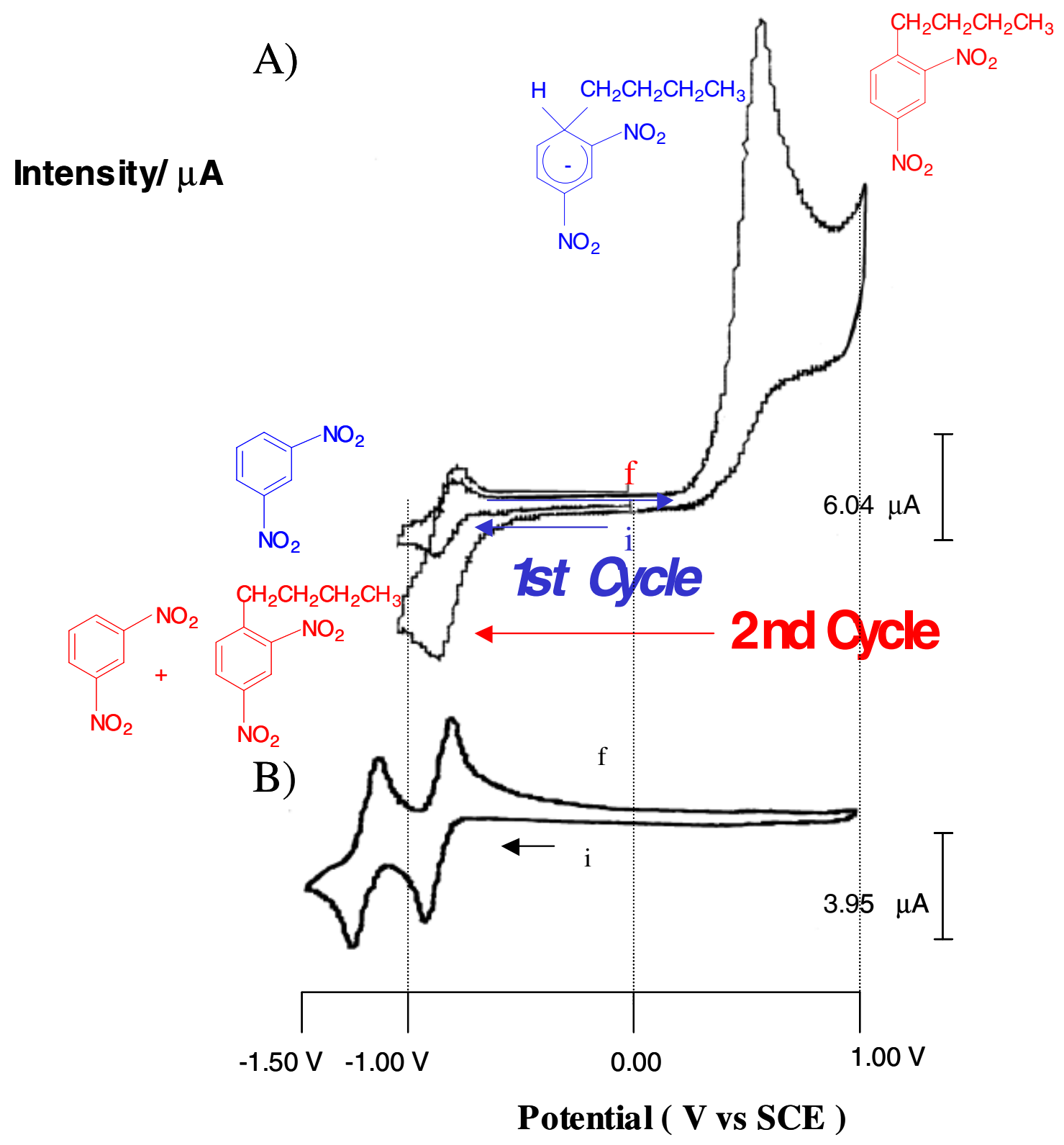




\section{Figure S1}

a) Cyclic voltammetry of the mixture between 1,3-dinitrobenzene $(20.0 \mathrm{mM})$ and $\mathrm{BuLi}(1: 1)$ in THF/DMF mixture under inert atmosphere $+0.4 \mathrm{M} \mathrm{nEtN}_{4} \mathrm{BF}_{4}$ at $10^{\circ} \mathrm{C}$. Scan rate $1.0 \mathrm{Vs}^{-1}$, glassy carbon disk electrode (0.05 mm diameter). The scan is in the potential range: $0.00 /-1.00 / 1.70 / 0.00 \mathrm{~V}$ (2 cycles)

b) Cyclic voltammetry of $\mathbf{1}(6.0 \mathrm{mM})$ in $\mathrm{DMF}+0.1 \mathrm{M} \mathrm{nBu}_{4} \mathrm{NBF}_{4}$ at $13^{\circ} \mathrm{C}$. Scan rate $1.0 \mathrm{Vs}^{-1}$, glassy carbon disk electrode $(0.05 \mathrm{~mm}$ diameter). The scan is in the potential range: $0.00 /-1.50 / 1.50 / 0.00 \mathrm{~V}$

Figure S1b shows the electrochemical behaviour of pure1,3-dinitrobenzene starting with a reduction scan. On the cathodic scan two reversible one-electron waves at $\mathrm{Ep}=-0.88 \mathrm{~V}$ and $\mathrm{Ep}=-1.24 \mathrm{~V}$ vs SCE , which correspond to the radical-anion and dianion of 1,3-dinitrobenzene are found. However, on the anodic scan no oxidation waves appeared, which implies that the 1,3-dinitrobenzene is not oxidable in the potential range used.

Figure S1a shows on the first cathodic scan a reversible wave at $-0.88 \mathrm{~V}$, which corresponds to the unreacted 1,3-dinitrobenzene(compound in blue). In this sense, the calculation of the nucleophilic attack can be easily calculated by a comparison between the initial intensity value and the final value. On the anodic scan two waves appear at $0.56 \mathrm{~V}$ vs. SCE .Note that the first one corresponds to a $\sigma^{\mathrm{H}}$-adduct (compound in blue) and leads to the substitution product (alkyl nitroaromatic compound (compound in red)). On a second reduction scan a reduction wave appears at c.a $0.89 \mathrm{~V}$ (compounds in red), which corresponds to the rearomatizated compound and the unreacted starting material.

After this simple voltammetric analysis, an exhaustive electrolysis at $1.50 \mathrm{~V}$ was performed. It is important to remark that before performing the electrolysis all the samples were analysed by means of cyclic voltammetry. 